\title{
Deliquescence of malonic, succinic, glutaric, and adipic acid particles
}

\author{
Matthew T. Parsons, Jackson Mak, Sarah R. Lipetz, and Allan K. Bertram \\ Department of Chemistry, University of British Columbia, Vancouver, British Columbia, Canada \\ Received 14 August 2003; revised 13 November 2003; accepted 13 January 2004; published 27 March 2004.
}

[1] In order to understand and predict the role of organic particles in the atmosphere their deliquescence behavior must be understood. Using an optical microscope coupled to a flow cell, we investigated the deliquescence of malonic, succinic, glutaric, and adipic acid particles with sizes ranging from 2 to $40 \mu \mathrm{m}$. Deliquescence relative humidities were determined for temperatures ranging from 293 to $243 \mathrm{~K}$. Over this temperature range both succinic acid and adipic acid deliquesced at approximately $100 \%$ relative humidity, whereas malonic acid and glutaric acid deliquesced at significantly lower relative humidities. These results are generally in good agreement with previous studies and are within 3\% of calculations based on the UNIQUAC (universal quasi-chemical) Functional Group Activity Coefficients (UNIFAC) model and recently published interaction parameters. Our studies also include measurements at temperatures below the eutectic temperatures. At these temperatures, ice did not nucleate; rather the particles underwent deliquescence to form metastable solution droplets. This indicates that solid dicarboxylic acids are not good ice nuclei above $243 \mathrm{~K}$ and hence will probably not play a role in ice cloud formation at these temperatures. INDEX TERMS: 0305 Atmospheric Composition and Structure: Aerosols and particles (0345, 4801); 0320 Atmospheric Composition and Structure: Cloud physics and chemistry; 0345 Atmospheric Composition and Structure: Pollution — urban and regional (0305); 0365 Atmospheric Composition and Structure: Troposphere-composition and chemistry; 1610 Global Change: Atmosphere (0315, 0325); KEYWORDS: deliquescence, optical microscopy, aerosol, atmospheric chemistry, ice nucleation, dicarboxylic acid

Citation: Parsons, M. T., J. Mak, S. R. Lipetz, and A. K. Bertram (2004), Deliquescence of malonic, succinic, glutaric, and adipic acid particles, J. Geophys. Res., 109, D06212, doi:10.1029/2003JD004075.

\section{Introduction}

[2] Condensed phase organic material is abundant in the atmosphere. In urban areas of the U.S., for example, organic material typically accounts for $10-40 \%$ of the fine particle mass, and in rural and remote areas of the U.S., organic material typically accounts for $30-50 \%$ of the fine particulate mass [Environmental Protection Agency, 1996]. Furthermore, in certain areas, such as the Amazon basin, the organic fraction can approach $90 \%$ of the total aerosol mass [Artaxo et al., 1988; Talbot et al., 1988]. The total amount of condensed phase organic material produced from these sources is estimated to be $175 \mathrm{Tg} \mathrm{yr}^{-1}$ [Kanakidou et al., 2000; Liousse et al., 1996].

[3] Despite the abundance of condensed-phase organic material in the atmosphere, relatively little is known about the possible phase transitions of organic particles. In order to understand and predict the role of organic particles in the atmosphere, these phase transitions must be understood. For example, recent laboratory studies have shown that the hydrolysis of $\mathrm{N}_{2} \mathrm{O}_{5}$ to form $\mathrm{HNO}_{3}$ will vary dramatically depending on whether or not particles are solid or aqueous solution droplets [Hanson and Ravishankara, 1993; Mozurkewich and Calvert, 1988]. Radiative forcing

Copyright 2004 by the American Geophysical Union. 0148-0227/04/2003JD004075\$09.00 by atmospheric particles and the mechanism of ice nucleation on or in these particles will also depend strongly on the phase and water content [DeMott, 2002; Martin, 1998; Tabazadeh and Toon, 1998; Zuberi et al., 2001].

[4] We have carried out a series of experiments to determine the deliquescence properties of pure dicarboxylic acid particles. Deliquescence is an atmospherically relevant phase transition that involves the uptake of water by solid particles to form solution droplets. These studies should lead to a better understanding of the more complex organic particles found in the atmosphere. Specifically, we focused on malonic, succinic, glutaric, and adipic acid particles. These organic compounds were chosen since field measurements have shown that these acids are a significant component of fine particulate matter in the troposphere [Chebbi and Carlier, 1996; Kawamura et al., 1996b; Saxena and Hildemann, 1996; Yao et al., 2002]. Sources of these dicarboxylic acids include biomass burning, fossil fuel combustion, and photochemical oxidation of gas-phase hydrocarbons [Chebbi and Carlier, 1996; Hatakeyama et al., 1985; Kawamura and Kaplan, 1987; Kawamura et al., 1996a].

[5] The deliquescence of dicarboxylic acid particles have previously been studied using a tandem differential mobility analyzer [Cruz and Pandis, 2000; Prenni et al., 2001], an electrodynamic balance [Peng et al., 2001], an aerosol flow tube-FTIR system [Braban et al., 2003], a static mode 
chamber-FTIR system [Braban et al., 2003], and bulk methods [Braban et al., 2003; Brooks et al., 2002; Peng et al., 2001; Wise et al., 2003]. In contrast, we used an optical microscope to study particles with sizes ranging from 2 to $40 \mu \mathrm{m}$. We investigated deliquescence at temperatures ranging from 293 to $243 \mathrm{~K}$, which extends the temperature range covered in most previous studies. These studies include measurements below the eutectic temperatures. At such temperatures the vapor is supersaturated with respect to ice prior to deliquescence, and hence, ice could nucleate. Currently, there is a dearth of experimental data on deliquescence at temperatures below the eutectic. In the following we present the deliquescence measurements and compare these measurements with previous studies and theoretical calculations.

\section{Experimental Setup}

[6] The apparatus used in these studies is illustrated in Figures $1 \mathrm{a}$ and $1 \mathrm{~b}$. The particles of interest are deposited on the bottom surface of the flow cell, the relative humidity in the cell is controlled by the continuous flow of a mixture of dry and humidified $\mathrm{N}_{2}$, and the phase of the particles is monitored with an optical microscope. This approach is similar to the approach recently used to study the microphysics of $\mathrm{NaCl}-\mathrm{H}_{2} \mathrm{O}$ and $\mathrm{HNO}_{3}-\mathrm{H}_{2} \mathrm{O}$ particles [Koop et al., 2000; Salcedo et al., 2000, 2001]. This methodology enables long observation times, temperature cycling, control of the relative humidity, and statistically significant results (typically 30-80 particles are monitored in a single experiment).

[7] The cell body and the inlet and outlet were constructed of stainless steel. The top window was sealed to the cell body with high vacuum grease (Dupont, Krytox LVP, vapor pressure less than $10^{-13}$ torr) and the bottom surface was sealed with a Viton O-ring. Two different bottom surfaces were used in these experiments: the first surface consisted of a thin glass cover slide treated with an organosilane to form a monomolecular hydrophobic layer, and the second surface consisted of a $0.03 \mathrm{~mm}$ polytetrafluoroethylene (PTFE) film annealed to a plain glass cover slide. The annealing process significantly reduced the number of defects on the surface of the PTFE film and provided adhesion between the glass substrate and the film. These hydrophobic surfaces were chosen to prevent ice nucleation directly on the bottom surface at sub-eutectic temperatures. We have also performed measurements at room temperature on several different substrates, ranging from hydrophobic (PTFE film) to hydrophilic (bare glass). In all cases, we observed the same result, indicating that the surface did not influence deliquescence.

[8] The relative humidity $(\mathrm{RH})$ over the particles was controlled by continuously flowing a mixture of dry and humidified $\mathrm{N}_{2}$ through the cell (total flow rate of 100 to $300 \mathrm{~cm}^{3} \mathrm{~min}^{-1}$ standard temperature and pressure). Ultrahigh purity nitrogen (Praxair, 99.999\%) was first passed through a hydrocarbon filter (Supelco, Supelcarb HC 24449) and then subsequently split into two flows. One flow was passed through a water bubbler situated inside a refrigerating circulator (Thermo Neslab, RTE-140) to generate humidified $\mathrm{N}_{2}$, and the second flow served as the dry $\mathrm{N}_{2}$ line. The relative humidity in the cell was varied by adjusting the (a)

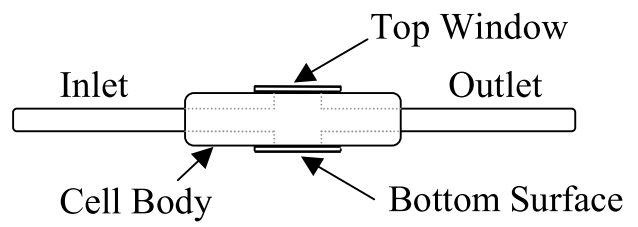

(b)

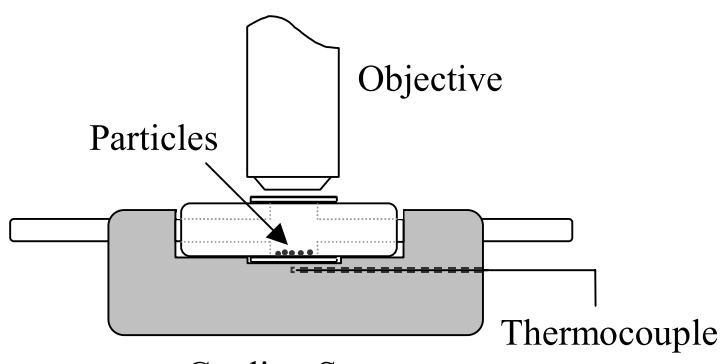

Cooling Stage

Figure 1. Diagram of the flow cell and experimental apparatus: (a) side view of the flow cell and (b) side view of the assembled apparatus.

relative flows of the dry and humidified $\mathrm{N}_{2}$ or adjusting the temperature of the circulator, while maintaining a constant total flow. A dew point hygrometer (General Eastern, Hygro M4) was used to determine the RH of the combined flows. This instrument measured the dew point or ice frost point of the gas, from which the relative humidity was calculated with the Goff and Gratch equations [Goff and Gratch, 1946] and knowledge of the substrate temperature.

[9] The sample cell was mounted on a cooling stage for temperature control. The temperature of the cooling stage and hence the sample cell was regulated with a refrigerating circulator (Thermo Neslab RTE-740). A type T thermocouple located in the cooling stage just below the flow cell was used to determine the temperature of the bottom surface of the flow cell. This thermocouple was calibrated against the dew point or ice frost point, as done previously in the literature [Middlebrook et al., 1993]. Briefly, calibration involved the following steps: first a constant relative humidity was established in the flow cell. Next the temperature of the flow cell was decreased until liquid water or ice particles condensed on the bottom surface of the cell due to heterogeneous nucleation on the PTFE film. The temperature of the flow cell was then slowly increased while visually monitoring the size of the particles with a reflected-light microscope (see below). From these observations we determined the temperature at which water particles neither grew nor shrunk in size. Under these conditions the particles were in equilibrium with the gasphase water vapor, and the temperature of the bottom surface of the cell was equal to the dew point or ice frost point, which was determined with the hygrometer. The difference between the temperature measured with the thermocouple and the dew point or ice frost point was used to construct a calibration curve for the thermocouple. 
At $273 \mathrm{~K}$ the correction was $0.1 \mathrm{~K}$, and at $243 \mathrm{~K}$ the correction was $0.7 \mathrm{~K}$.

[10] Deliquescence of the particles was monitored with a reflected-light microscope (Zeiss, Axiotech 100) equipped with a 20 times and a 50 times objective. Images of the particles were recorded with a CCD camera attached to a monitor and video recorder, and the temperature and dew point/ice frost point were recorded simultaneously. From the images we determined the size and morphology of the particles and the deliquescence relative humidities. In most of the experiments we used polarized light to enhance the contrast between solid and liquid particles; however, phase transitions were also discernable with unpolarized light as demonstrated previously [Bertram et al., 2000; Koop et al., 2000, 1998]. Shown in Figures 2a, 2b, and 2c are images recorded during a typical experiment. Figure $2 \mathrm{a}$ shows images of ammonium sulfate particles prior to deliquescence; Figure $2 \mathrm{~b}$ shows images during deliquescence; and Figure $2 \mathrm{c}$ shows images after deliquescence.

[11] Particles ranging in size from 2 to $40 \mu \mathrm{m}$ were produced by two methods. The first method consisted of grinding crystals and placing the resulting particles directly on the bottom surface prior to assembling the flow cell. The second method involved directing a stream of submicron particles from an atomizer (TSI 7660), at the PTFE substrate for $1-5 \mathrm{~s}$. During this time the submicron particles impacted on the surface and coagulated resulting in supermicron particles. Solutions used in the atomizer were made with either deionized ultrafiltered water (Fisher) or HPLC-grade water (Fisher), both of which have been passed through a submicron filter. The results were independent of the grade of water used. Ammonium sulfate (Fisher, 99.8\%), malonic acid (Aldrich, 99\%), succinic acid (Fisher, 99.8\%), glutaric acid (Aldrich, 99\%), and adipic acid (Fisher, 99.9\% minimum) were all used as supplied without further purification. Ammonium sulfate was used to validate our experimental setup as discussed below.

[12] The size of atmospheric particles range from approximately 0.002 to $10 \mu \mathrm{m}$ [Finlayson-Pitts and Pitts, 2000]. As mentioned, the size of the particles used in our experiments ranged from 2 to $40 \mu \mathrm{m}$. Hence the smallest particles studies in our experiments fall within the size range that is important for atmospheric chemistry and physics. Furthermore, our deliquescence results were independent of particle size, suggesting that our results could be applicable to smaller particles.

[13] During a deliquescence experiment the relative humidity was first held close to $0 \%$ to ensure all the particles were solid. Then the relative humidity was increased by either adjusting the dry and humidified $\mathrm{N}_{2}$ flows or adjusting the temperature of the humidifying bubbler. Close to deliquescence the relative humidity was increased at a rate of approximately $0.05 \%$ per minute. The uncertainty in our deliquescence measurements $( \pm 2 \sigma)$ was approximately $\pm 2.1 \%$ relative humidity, based on repeated measurements at a fixed temperature.

[14] For measurements below the eutectic temperatures we modified our setup slightly. In these experiments a $2 \mathrm{~mm}$ thick PTFE spacer was inserted between the stainless steel cell body and the bottom surface. The PTFE spacer maintained a large temperature differential (at least $10 \mathrm{~K}$ ) between the cell body and the bottom substrate. This

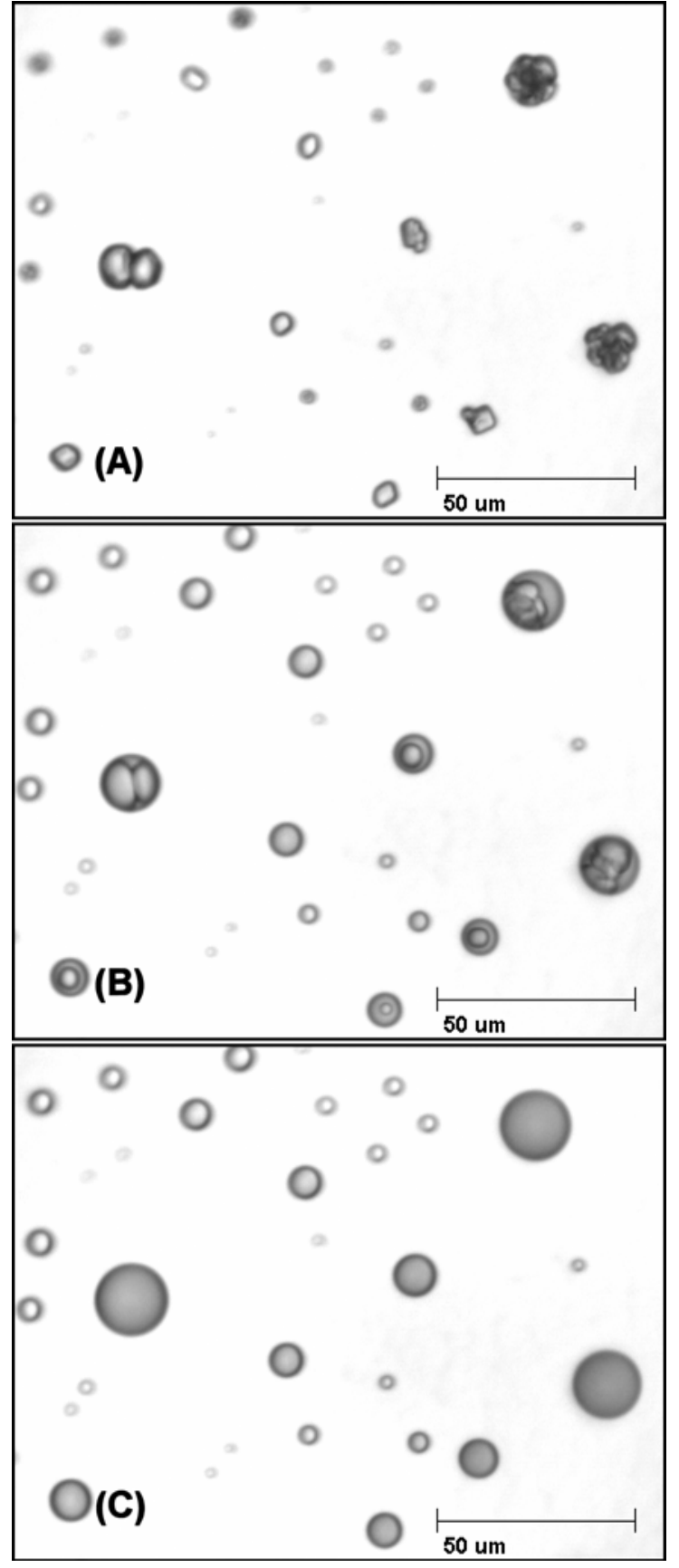

Figure 2. Images of ammonium sulfate particles recorded during a deliquescence experiment: (a) solid particles prior to deliquescence, (b) solid-liquid particles during deliquescence, and (c) liquid particles just after complete deliquescence.

ensured that ice did not nucleate directly on the cell body and ice supersaturation was maintained above the organic particles.

\section{Results and Discussion}

\subsection{Deliquescence of Ammonium Sulfate Particles}

[15] In order to evaluate the performance of our experimental apparatus and approach, we first studied ammonium sulfate particles. The deliquescence of these particles has 


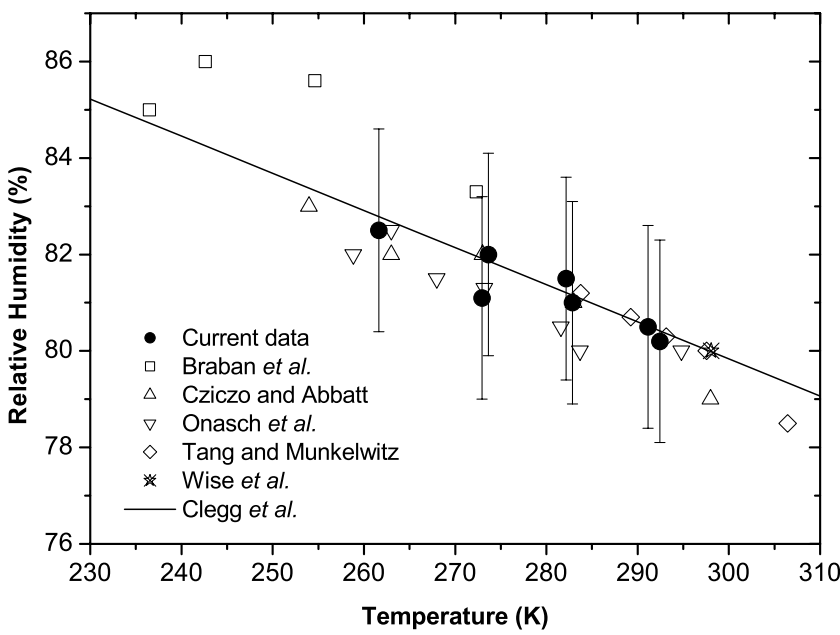

Figure 3. Deliquescence of ammonium sulfate particles as a function of temperature. Our data were obtained with particles ranging in size from 2 to $40 \mu \mathrm{m}$. The uncertainty in our deliquescence measurements $( \pm 2 \sigma)$ was approximately $\pm 2.1 \%$ relative humidity, based on repeated measurements at a fixed temperature. The results from Braban et al. [2001] and Tang and Munkelwitz [1993] were also obtained with supermicron particles, and the data from both Cziczo and Abbatt [1999] and Onasch et al. [1999] were obtained using submicron particles. The results from Wise et al. [2003] were obtained with bulk solutions. The solid line was calculated using a thermodynamic model by Clegg et al. [1998].

been studied extensively and is well understood [Martin, 2000]. The deliquescence results are shown in Figure 3. Also shown are experimental results from other groups and predictions based on thermodynamic considerations. The results from Braban et al. [2001] and Tang and Munkelwitz [1993] were obtained with supermicron particles; the data from both Cziczo and Abbatt [1999] and Onasch et al. [1999] were obtained using submicron aerosol particles; and the data from Wise et al. [2003] were obtained using bulk solutions. The solid line was calculated using a thermodynamic model by Clegg et al. [1998]. Our results are in excellent agreement with the previous experimental measurements and the theoretical predictions.

\subsection{Deliquescence of Dicarboxylic Acid Particles as a Function of Temperature}

[16] The deliquescence relative humidities (DRH) for the four organic acids studied are shown in Figures 4-7. Succinic acid and adipic acid deliquesce close to $100 \%$ RH; whereas malonic acid and glutaric acid deliquesce at lower relative humidities, consistent with the solubilities of these organics. The high DRH values for both adipic acid and succinic acid suggest that these organics may exist as solids in atmospheric particles if these organics are a significant component of the aerosol mass. For comparison, the solubilities for malonic, succinic, and adipic acid at 298.15 K are 0.2176, 0.01337, and 0.00307 mole fraction acid, respectively [Apelblat and Manzurola, 1987]; and the solubility for glutaric acid at $297.05 \mathrm{~K}$ is 0.1506 mole fraction acid [Stephen and Stephen, 1963].

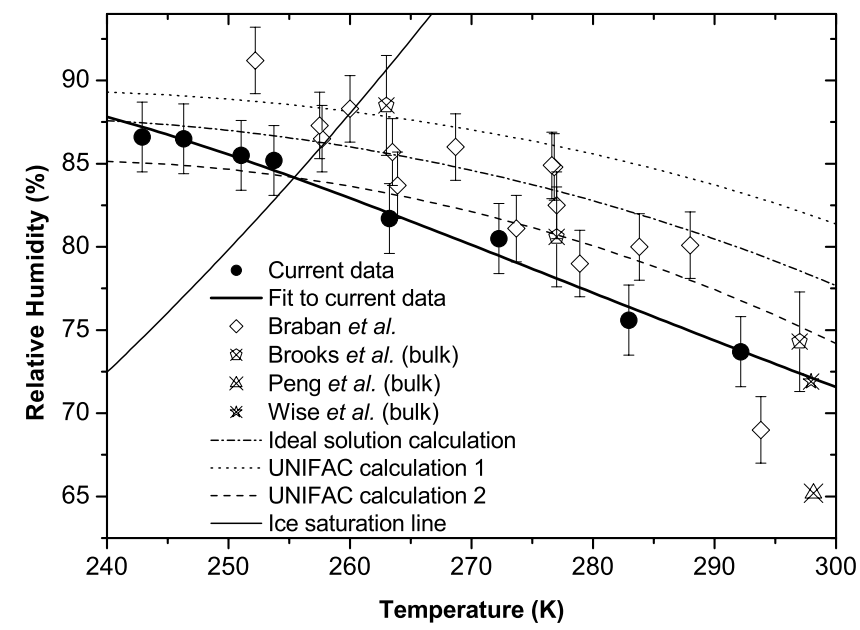

Figure 4. Deliquescence of malonic acid as a function of temperature. Our data were obtained with particles ranging in size from 2 to $40 \mu \mathrm{m}$. The results from Braban et al. [2003] were obtained using submicron and supermicron particles, and the data from Brooks et al. [2002], Wise et al. [2003], and Peng et al. [2001] were obtained using bulk solutions. Details of the theoretical calculations are given in the text.

[17] As done previously in the literature for inorganic salts [Tabazadeh and Toon, 1998; Onasch et al., 1999], we fit the temperature-dependent DRH data for malonic and glutaric acid to the following equation:

$$
\ln (\mathrm{DRH})=A+\frac{B}{T}+\frac{C}{T^{2}}+\frac{D}{T^{3}}
$$

where $\mathrm{DRH}$ is the deliquescence relative humidity (\%) and $T$ is the temperature $(\mathrm{K})$. The solid thick lines shown in

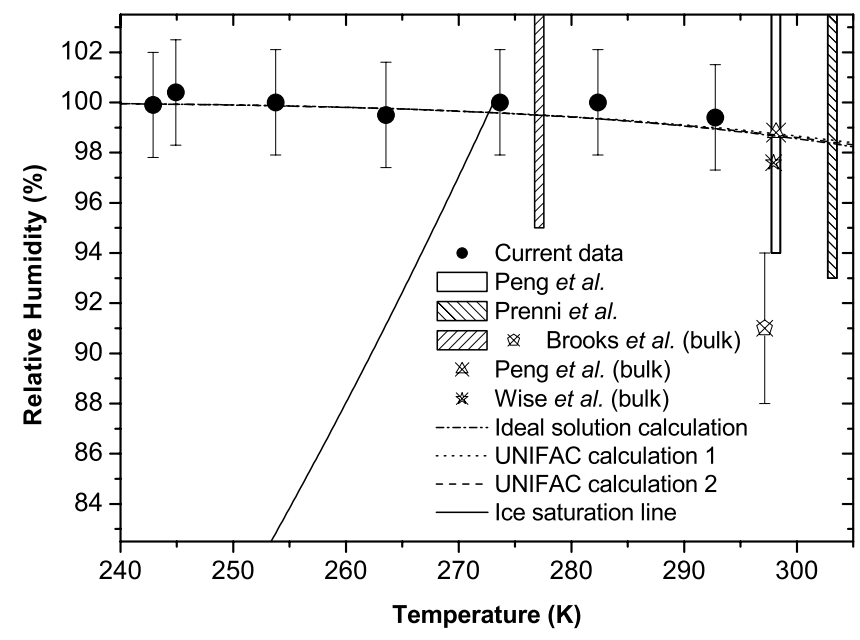

Figure 5. Deliquescence of succinic acid as a function of temperature. Our data were obtained with supermicron particles $(2-40 \mu \mathrm{m})$. The results from Peng et al. [2001] were obtained using supermicron particles and bulk solutions. The data from Prenni et al. [2001] were obtained using submicron particles, and the data from Brooks et al. [2002] and Wise et al. [2003] were obtained using bulk methods. The overlapping theoretical calculations are described in the text. 


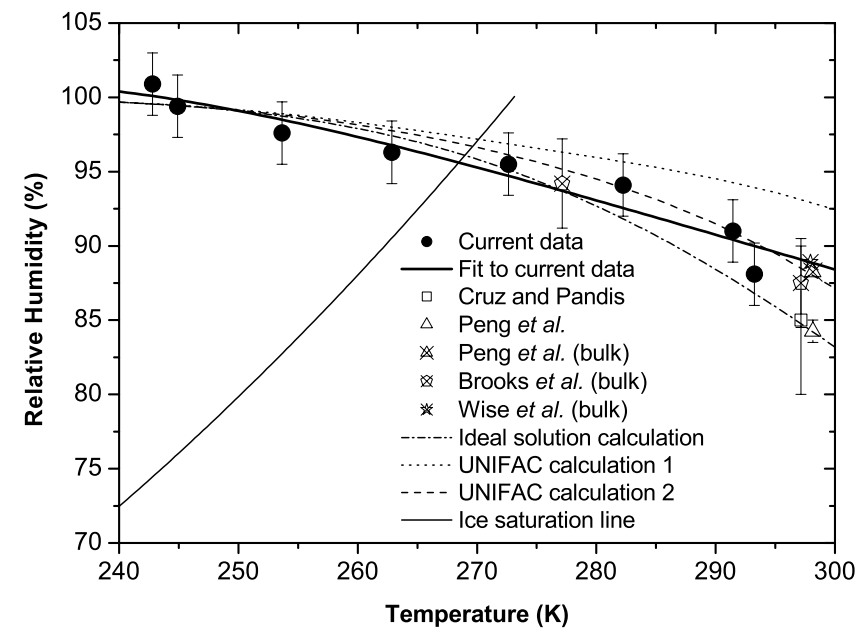

Figure 6. Deliquescence of glutaric acid as a function of temperature. Our data were obtained with particles ranging in size from 2 to $40 \mu \mathrm{m}$. The results from Cruz and Pandis [2000] were obtained using submicron aerosol particles. The results from Peng et al. [2001] were obtained using supermicron particles and bulk solutions, and the data from Brooks et al. [2002] and Wise et al. [2003] were obtained using bulk methods.

Figures 4 and 6 are the results from this least squares analysis, and the parameters that describe these curves are given in Table 1. We did not perform a similar analysis for succinic and adipic acid since within experimental uncertainty the DRH for these particles was $100 \%$ and independent of temperature.

[18] Also shown in Figures 4-7 are results from other groups. Cruz and Pandis [2000] as well as Prenni et al. [2001] investigated the deliquescence of submicron particles using a tandem differential mobility analyzer system.

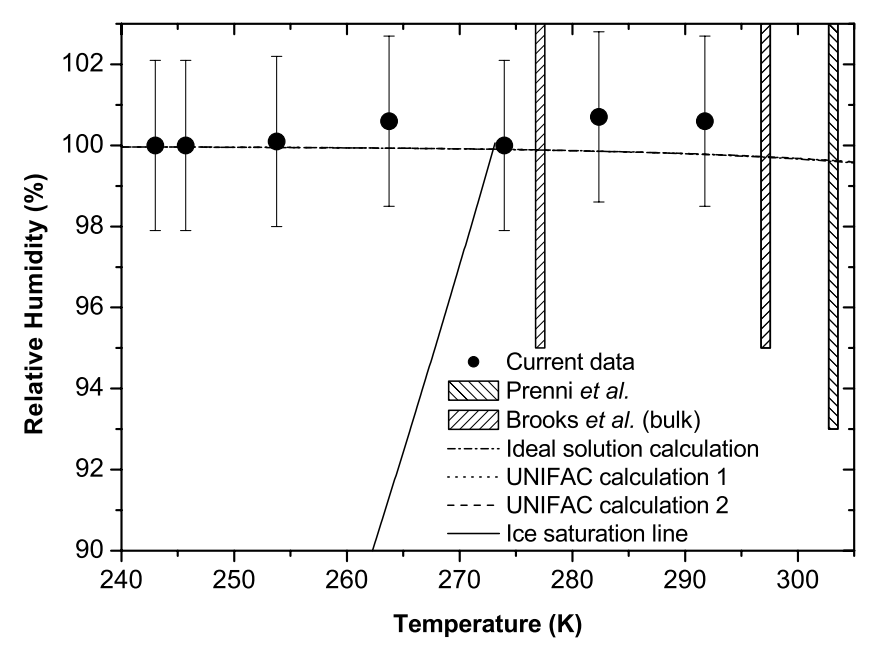

Figure 7. Deliquescence of adipic acid as a function of temperature. Our data were obtained with particles ranging in size from 2 to $40 \mu \mathrm{m}$. The results from Prenni et al. [2001] were obtained with submicron aerosol particles, and the data from Brooks et al. [2002] were obtained using bulk methods. The overlapping theoretical calculations are described in the text.
Table 1. Parameters Describing the Deliquescence Results ${ }^{\mathrm{a}}$

\begin{tabular}{ccccc}
\hline Acid & A & B & C & D \\
\hline Malonic acid & 2.5930 & 463.17 & $7.1176 \times 10^{4}$ & $-1.7740 \times 10^{7}$ \\
Glutaric acid & 3.1912 & 384.68 & $4.6458 \times 10^{4}$ & $-1.3706 \times 10^{7}$ \\
\hline
\end{tabular}

${ }^{\mathrm{a}}$ Deliquescence relative humidity can be calculated from $\ln (\mathrm{DRH})=\mathrm{A}+$ $\mathrm{B} / \mathrm{T}+\mathrm{C} / \mathrm{T}^{2}+\mathrm{D} / \mathrm{T}^{3}$, where $\mathrm{DRH}$ is the deliquescence relative humidity (in percent $\mathrm{RH}$ ) and $\mathrm{T}$ is the temperature (in $\mathrm{K}$ ).

Peng et al. [2001] investigated the deliquescence using an electrodynamic balance and bulk methods, and Brooks et al. [2002] and Wise et al. [2003] determined the deliquescence relative humidity of these acids from bulk measurements. Braban et al. [2003] measured the deliquescence properties of submicron and supermicron particles using an aerosol flow tube-FTIR system and a static mode chamber-FTIR system. In several of the measurements mentioned above only lower limits to deliquescence were determined. These limits are represented by the hatched bars in Figures 5 and 7.

[19] In general, our results are in good agreement with the results from previous studies. Our malonic acid results are consistent with the measurements from Braban et al. [2003], Brooks et al. [2002], and Wise et al. [2003]. The results from Peng et al. [2001] appear to be 5\% lower than our measurements. Our succinic acid results are consistent with the measurements by Peng et al. [2001], Prenni et al. [2001], and Wise et al. [2003]; however, our results are approximately $7 \%$ above the measurement at $298 \mathrm{~K}$ by Brooks et al. [2002]. For glutaric acid, our results are consistent with the results reported by Brooks et al. [2002], and our results when extrapolated to warmer temperatures are consistent with the results reported by Cruz and Pandis [2000], Peng et al. [2001], and Wise et al. [2003]. Finally, our results for adipic acid are consistent with the lower limits reported by Prenni et al. [2001] and Brooks et al. [2002]. As mentioned above, the experimental results presented in Figures 4-7 were obtained using submicron and supermicron particles as well as bulk solutions. The good agreement between these results illustrates that there is no significant kinetic barrier to the deliquescence of dicarboxylic acid particles and that bulk thermodynamics can be used to predict the DRH of these particles. Braban et al. [2003] recently reached a similar conclusion for the malonic acid system.

\subsection{Theoretical Calculations of DRH}

[20] We first calculated the deliquescence relative humidities of the dicarboxylic acid particles using solubility data and by assuming the saturated solutions obey Raoult's law (ideal solution). Solubility data for malonic, succinic, and adipic acid where taken from Apelblat and Manzurola [1987], and solubility data for glutaric acid were taken from Stephen and Stephen [1963]. Apelblat and Manzurola [1987] reported solubility data from 298.15 to $278.15 \mathrm{~K}$, and Stephen and Stephen [1963] reported solubility data from 318.95 to $276.55 \mathrm{~K}$. The solubility data were fit to the following equation:

$$
\ln (x)=A+\frac{B}{T}+\frac{C}{T^{2}}
$$

where $x$ is the solubility (mole fraction) and $T$ is the temperature (Kelvin). The parameters from the least squares 
analysis were used when calculating deliquescence. Equation (2) was chosen for this study because it fit the solubility data well $\left(R^{2}\right.$ ranged from 0.9963 to 0.9999$)$ and because it gave realistic solubilities when extrapolated to low temperatures. In contrast, other equations we tried gave either negative solubilities when extrapolated to $243 \mathrm{~K}$ or solubilities that increased with decreasing temperature at low temperatures. The relative uncertainty of the solubility data for malonic, succinic, glutaric, and adipic acid are approximately $1 \%, 1 \%, 4 \%$, and $3 \%$, respectively, based on the scatter in the data.

[21] Calculations based on solubility data and Raoult's law are shown in Figures 4-7 (labeled ideal solution calculation). The uncertainties in the calculations due to the uncertainties in the solubility data are estimated to be less than $1 \%$. These calculations accurately describe the deliquescence of succinic acid and adipic acid, which is not surprising since these particles are dilute solutions at deliquescence. The calculation also appears to agree reasonably well with the glutaric acid measurements (the calculations fall within our error bars except for two data points); however, for malonic acid the calculations are significantly above the measurements at temperatures greater than $270 \mathrm{~K}$, indicating that saturated solutions of malonic acid do not obey Raoult's law.

[22] We have also calculated the DRH of these dicarboxylic acid particles as a function of temperature using the solubility data described above and the original UNIQUAC (universal quasi-chemical) Functional Group Activity Coefficients (UNIFAC) model [Fredenslund et al., 1975]. The UNIFAC model is a group contribution method that is used for predicting thermodynamic properties of nonideal solutions. Here we use the UNIFAC model to calculate the water activity of saturated solutions of dicarboxylic acids. Note that the water activity at saturation is equal to DRH divided by 100 . The use of UNIFAC has been described in detail [Fredenslund et al., 1977, 1975; Fredenslund and Sorensen, 1994].

[23] In order to calculate the water activity of an organicwater solution using UNIFAC, group volume parameters, group area parameters, and group interaction parameters are required. For the first set of UNIFAC calculations shown in Figures 4-7 (UNIFAC calculation 1) we used group volume, group area, and group interaction parameters from Reid et al. [1987]. For the second set of UNIFAC calculations shown in Figures 4-7 (UNIFAC calculation 2) we used group volume and group area parameters from Reid et al. and group interaction parameters from Peng et al. [2001]. The calculations based on the interaction parameters from Reid et al. [1987] deviate from our glutaric acid results at temperatures greater than $285 \mathrm{~K}$, and deviate significantly from our malonic acid results over the entire temperature range studied. This is not surprising since recently it was shown that water activity predictions for malonic and glutaric acid based on parameters from Reid et al. deviate from water activity measurements [Peng et al., 2001]. In contrast, the calculations based on the parameters from Peng et al. are in good agreement with the experimental results for glutaric acid, and the calculations are within $3 \%$ of the experimental results for malonic acid.

[24] We also calculated the DRH for these acids using interaction parameters reported by Ming and Russell [2002], group volume and group area parameters from Reid et al. [1987], and the solubility data described above. The results from this third set of UNIFAC calculations (not shown) fell between the results from the first two sets of UNIFAC calculations (UNIFAC calculations 1 and 2).

[25] The UNIFAC model combined with interaction parameters from Peng et al. [2001] gave the best agreement with our experimental results. The reasonable agreement suggests that the UNIFAC model combined with appropriate interaction parameters should be a useful tool for calculating the deliquescence properties of multicomponent organic particles found in the atmosphere.

\subsection{DRH Values Below the Eutectic Temperature}

[26] As mentioned above, at temperatures below the eutectic the vapor is supersaturated with respect to ice prior to deliquescence. At these temperatures ice may nucleate directly on the solid organic particles prior to deliquescence. Furthermore, if these solid dicarboxylic acids are good ice nuclei then they may play an important role in ice cloud formation in the atmosphere.

[27] The eutectic temperature for each system was identified by determining the temperature at which the vapor pressure of ice equals the partial pressure of water over the saturated organic solution. The vapor pressure of ice as a function of temperature was calculated with the Goff and Gratch equation [Goff and Gratch, 1946]. The partial pressure of water over the saturated aqueous solutions as a function of temperature was determined from our deliquescence results. On the basis of these results, the eutectic temperatures for malonic, succinic, glutaric, and adipic acid are $255.7,273.2,269.0$, and $273.2 \mathrm{~K}$, respectively. Also shown in Figures $4-7$ is the ice saturation line from the Goff and Gratch equation. This line illustrates the conditions at which the vapor is supersaturated with respect to ice.

[28] At temperatures below the eutectic temperature ice was not observed in any of our experiments rather the particles underwent deliquescence to form metastable solution droplets. Furthermore, the measured DRH was in agreement with the DRH predicted with the UNIFAC model and interaction parameters from Peng et al. [2001] (see above). Deliquescence below the eutectic has also been observed for the malonic acid-water system [Braban et al., 2003], the ammonium sulfate-water system [Braban et al., 2001; Fortin et al., 2002], and the sodium chloride-water system [Koop et al., 2000].

[29] Our measurements at temperatures below the eutectic indicate that solid dicarboxylic acids (with surface structures similar to the surface structures employed in our studies) will not play an important role in ice cloud formation at temperatures above $243 \mathrm{~K}$. These solid acids may be important in ice cloud formation at temperatures below $243 \mathrm{~K}$, or if the particles are preactivated or have significantly more defects than the particles in our studies [Zuberi et al., 2001].

\section{Summary and Conclusions}

[30] Deliquescence relative humidities for malonic, glutaric, succinic, and adipic acid particles were determined for temperatures ranging from 293 to $243 \mathrm{~K}$. Over this temper- 
ature range both succinic acid and adipic acid deliquesced at approximately $100 \%$ relative humidity. In contrast, the DRH for malonic acid at $293 \mathrm{~K}$ and $243 \mathrm{~K}$ was $73.7 \%$ and $86.6 \%$, respectively, and the DRH for glutaric acid at $293 \mathrm{~K}$ and $243 \mathrm{~K}$ was $91.0 \%$ and $100 \%$, respectively. Our results are in good agreement with previous studies which used bulk solutions, supermicron particles and submicron particles. This agreement suggests that there is no significant kinetic barrier to the deliquescence of these dicarboxylic acid particles. The deliquescence measurements were compared with a series of theoretical calculations. The UNIFAC model combined with interaction parameters from Peng et al. [2001] gave the best agreement with the experimental results. The reasonable agreement suggests that the UNIFAC model combined with appropriate interaction parameters should be a useful tool for calculating the deliquescence properties of multicomponent organic particles found in the atmosphere.

[31] At temperatures below the eutectic, ice was not observed in any of our experiments, rather the particles underwent deliquescence to form metastable solution droplets. This indicates that the solid organics studied are not good ice nuclei above $243 \mathrm{~K}$ and hence will probably not play a role in ice cloud formation at these temperatures.

[32] Acknowledgments. We thank M. Eastwood and L. Sun for their assistance in equipment design and substrate selection and A. Fok for help with some of the deliquescence measurements. We also thank C. F. Braban, J. P. D. Abbatt, M. E. Wise, and M. A. Tolbert for providing us with manuscripts prior to publication and L. M. Russell for helpful discussions. This research was supported by the Natural Sciences and Engineering Research Council of Canada, the Canadian Research Chair Program, and the Canadian Foundation for Innovation.

\section{References}

Apelblat, A., and E. Manzurola (1987), Solubility of oxalic, malonic, succinic, adipic, maleic, malic, citric, and tartaric acids in water from 278.15 to $338.15 \mathrm{~K}, \mathrm{~J}$. Chem. Thermodyn., 19, 317-320.

Artaxo, P., H. Storms, F. Bruynseels, R. V. Grieken, and W. Maenhaut (1988), Composition and source of aerosols from the Amazon basin, J. Geophys. Res., 93, 1605-1615.

Bertram, A. K., T. Koop, L. T. Molina, and M. J. Molina (2000), Ice formation in (NH4) (2) $\mathrm{SO}_{4}-\mathrm{H}_{2} \mathrm{O}$ particles, J. Phys. Chem. A, 104(3), $584-588$.

Braban, C. F., J. P. D. Abbatt, and D. J. Cziczo (2001), Deliquescence of ammonium sulfate particles at sub-eutectic temperatures, Geophys. Res. Lett., 28(20), 3879-3882.

Braban, C. F., M. F. Carroll, S. A. Styler, and J. P. D. Abbatt (2003), Phase transitions of malonic and oxalic acid aerosols, J. Phys. Chem. A, 107, 6594-6602.

Brooks, S. D., M. E. Wise, M. Cushing, and M. A. Tolbert (2002), Deliquescence behavior of organic/ammonium sulfate aerosol, Geophys. Res. Lett., 29(19), 1917, doi:10.1029/2002GL014733.

Chebbi, A., and P. Carlier (1996), Carboxylic acids in the troposphere, occurrence, sources, and sinks: A review, Atmos. Environ., 30(24), 4233-4249.

Clegg, S. L., P. Brimblecombe, and A. S. Wexler (1998), Thermodynamic model of the system $\mathrm{H}_{+}-\mathrm{NH}_{4}^{+}-\mathrm{SO}_{4}^{2-}-\mathrm{NO}_{3}^{-}-\mathrm{H}_{2} \mathrm{O}$ at tropospheric temperatures, J. Phys. Chem. A, 102(12), 2137-2154.

Cruz, C. N., and S. N. Pandis (2000), Deliquescence and hygroscopic growth of mixed inorganic-organic atmospheric aerosol, Environ. Sci. Technol., 34(20), 4313-4319.

Cziczo, D. J., and J. P. D. Abbatt (1999), Deliquescence, efflorescence, and supercooling of ammonium sulfate aerosols at low temperature: Implications for cirrus cloud formation and aerosol phase in the atmosphere, J. Geophys. Res., 10(D11), 13,781-13,790.

DeMott, P. J. (2002), Laboratory studies of cirrus cloud processes, in Cirrus, edited by D. K. Lynch, K. Sassen, D. O. Starr, and G. Stephens, pp. 102-136, Oxford Univ. Press, New York.

Environmental Protection Agency (1996), Air quality criteria for particulate matter, Rep. EPA/600/P-95/001, Washington, D. C.
Finlayson-Pitts, B. J., and J. N. Pitts Jr. (2000), Chemistry of the Upper and Lower Atmosphere, Academic, San Diego, Calif.

Fortin, T. J., J. E. Shilling, and M. A. Tolbert (2002), Infrared spectroscopic study of the low-temperature phase behavior of ammonium sulfate, J. Geophys. Res., 107(D10), 4088, doi:10.1029/2001JD000677.

Fredenslund, A., and J. M. Sorensen (1994), Group contribution estimation methods, in Models for Thermodynamic and Phase Equilibria Calculations, edited by S. I. Sandler, pp. 287-361, Marcel Dekker, New York.

Fredenslund, A., R. L. Jones, and J. M. Prausnitz (1975), Group-contribution estimation of activity coefficients in nonideal liquid mixtures, $A I C h E$ J., 21, 1086-1099.

Fredenslund, A., J. Gmehling, and P. Rasmussen (1977), Vapor-Liquid Equilibria Using UNIFAC, Elsevier Sci., New York.

Goff, J. A., and S. Gratch (1946), Low-pressure properties of water from -160 to 212 F, Trans. Am. Soc. Heat. Ventil. Eng., 52, 95-122.

Hanson, D. R., and A. R. Ravishankara (1993), Reaction of $\mathrm{ClONO}_{2}$ with $\mathrm{HCl}$ on NAT, NAD, and frozen sulfuric acid and hydrolysis of $\mathrm{N}_{2} \mathrm{O}_{5}$ and $\mathrm{ClONO}_{2}$ on frozen sulfuric acid, J. Geophys. Res., 98(D12), 22,93122,936 .

Hatakeyama, S., T. Tanonaka, J. Weng, H. Bandow, H. Takagi, and H. Akimoto (1985), Ozone-cyclohexene reaction in air: Quantitative analysis of particulate products and the reaction mechanism, Environ. Sci. Technol., 19, 935-941.

Kanakidou, M., K. Tsigaridis, F. J. Dentener, and P. J. Crutzen (2000), Human-activity-enhanced formation of organic aerosols by biogenic hydrocarbon oxidation, J. Geophys. Res., 105(D7), 9243-9254.

Kawamura, K., and I. R. Kaplan (1987), Motor exhaust emission as a primary source for dicarboxylic acids in Los Angeles ambient air, Environ. Sci. Technol., 21, 105-110.

Kawamura, K., H. Kasukabe, and L. A. Barrie (1996a), Source and reaction pathways of dicarboxylic acids, ketoacids and dicarbonyls in arctic aerosols: One year of observations, Atmos. Environ., 30(10-11), $1709-1722$

Kawamura, K., R. Semere, Y. Imai, Y. Fujii, and M. Hayashi (1996b), Water soluble dicarboxylic acids and related compounds in Antarctic aerosols, J. Geophys. Res., 101(D13), 18,721-18,728.

Koop, T., H. P. Ng, L. T. Molina, and M. J. Molina (1998), A new optical technique to study aerosol phase transitions: The nucleation of ice from $\mathrm{H}_{2} \mathrm{SO}_{4}$ aerosols, J. Phys. Chem. A, 102(45), 8924-8931.

Koop, T., A. Kapilashrami, L. T. Molina, and M. J. Molina (2000), Phase transitions of sea-salt/water mixtures at low temperatures: Implications for ozone chemistry in the polar marine boundary layer, J. Geophys. Res., 105(D21), 26,393-26,402.

Liousse, C., J. E. Penner, C. Chuang, J. J. Walton, H. Eddleman, and H. Cachier (1996), A global three-dimensional model study of carbonaceous aerosols, J. Geophys. Res., 10(D14), 19,411-19,432.

Martin, S. T. (1998), Phase transformations of the ternary system $\left(\mathrm{NH}_{4}\right)_{2} \mathrm{SO}_{4}-\mathrm{H}_{2} \mathrm{SO}_{4}-\mathrm{H}_{2} \mathrm{O}$ and the implications for cirrus cloud formation, Geophys. Res. Lett., 25(10), 1657-1660.

Martin, S. T. (2000), Phase transitions of aqueous atmospheric particles, Chem. Rev., 100(9), 3403-3453.

Middlebrook, A. M., L. T. Iraci, L. S. McNeill, B. G. Koehler, M. A. Wilson, O. W. Saastad, M. A. Tolbert, and D. R. Hanson (1993), Fourier transform-infrared studies of thin $\mathrm{H}_{2} \mathrm{SO}_{4} / \mathrm{H}_{2} \mathrm{O}$ films-Formation, wateruptake, and solid-liquid phase-changes, J. Geophys. Res., 98(D11), 20,473-20,481.

Ming, Y., and L. M. Russell (2002), Thermodynamic equilibrium of organic-electrolyte mixtures in aerosol particles, AIChE J., 48, 13311348 .

Mozurkewich, M., and J. G. Calvert (1988), Reaction probability of $\mathrm{N}_{2} \mathrm{O}_{5}$ on aqueous aerosols, J. Geophys. Res., 93(D12), 15,889-15,896.

Onasch, T. B., R. L. Siefert, S. D. Brooks, A. J. Prenni, B. Murray, M. A. Wilson, and M. A. Tolbert (1999), Infrared spectroscopic study of the deliquescence and efflorescence of ammonium sulfate aerosol as a function of temperature, J. Geophys. Res., 104(D17), 21,317-21,326.

Peng, C., M. N. Chan, and C. K. Chan (2001), The hygroscopic properties of dicarboxylic and multifunctional acids: Measurements and UNIFAC predictions, Environ. Sci. Technol., 35(22), 4495-4501.

Prenni, A. J., P. J. DeMott, S. M. Kreidenweis, D. E. Sherman, L. M. Russell, and Y. Ming (2001), The effects of low molecular weight dicarboxylic acids on cloud formation, J. Phys. Chem. A, 105(50), 11,24011,248 .

Reid, R. C., J. M. Prausnitz, and B. E. Poling (1987), The Properties of Gases and Liquids, McGraw-Hill, New York.

Salcedo, D., L. T. Molina, and M. J. Molina (2000), Nucleation rates of nitric acid dihydrate in 1: $2 \mathrm{HNO}_{3} / \mathrm{H}_{2} \mathrm{O}$ solutions at stratospheric temperatures, Geophys. Res. Lett., 27(2), 193-196.

Salcedo, D., L. T. Molina, and M. J. Molina (2001), Homogeneous freezing of concentrated aqueous nitric acid solutions at polar stratospheric temperatures, J. Phys. Chem. A, 105(9), 1433-1439. 
Saxena, P., and L. M. Hildemann (1996), Water-soluble organics in atmospheric particles: A critical review of the literature and application of thermodynamics to identify candidate compounds, J. Atmos. Chem., 24(1), 57-109.

Stephen, H., and T. Stephen (1963), Solubilities of Inorganic and Organic Compounds, Macmillan, New York.

Tabazadeh, A., and O. B. Toon (1998), The role of ammoniated aerosols in cirrus cloud nucleation, Geophys. Res. Lett., 25(9), 1379-1382.

Talbot, R. W., M. O. Andreae, T. W. Andreae, and R. C. Harriss (1988), Regional aerosol chemistry of the Amazon Basin during the dry season, J. Geophys. Res., 93(D2), 1499-1508.

Tang, I. N., and H. R. Munkelwitz (1993), Composition and temperaturedependence of the deliquescence properties of hygroscopic aerosols, Atmos. Environ. Part A, 27(4), 467-473.
Wise, M. E., J. D. Surratt, D. B. Curtis, J. E. Shilling, and M. A. Tolbert (2003), Hygroscopic growth of ammonium sulfate/dicarboxylic acids, J. Geophys. Res., 108(D20), 4638, doi:10.1029/2003JD003775.

Yao, X. H., M. Fang, and C. K. Chan (2002), Size distributions and formation of dicarboxylic acids in atmospheric particles, Atmos. Environ., 36(13), 2099-2107.

Zuberi, B., A. K. Bertram, T. Koop, L. T. Molina, and M. J. Molina (2001), Heterogeneous freezing of aqueous particles induced by crystallized $\left(\mathrm{NH}_{4}\right)(2) \mathrm{SO}_{4}$, ice, and letovicite, J. Phys. Chem. A, 105(26), 6458-6464.

A. K. Bertram, S. R. Lipetz, J. Mak, and M. T. Parsons, Department of Chemistry, University of British Columbia, 2036 Main Mall, Vancouver, B.C., Canada V6T 1Z1. (bertram@chem.ubc.ca) 